\title{
PENUMBRA SOBRE LA ZONA CULTURAL DE LIMA. ANÁLISIS DE LOS PROCESOS DE GESTIÓN DE LA HUACA SAN BORJA [LIMA-PERÚ) ENTRE LOS AÑOS 1986-2016 ${ }^{(*)}$
}

\author{
SHADOWS ON THE CULTURAL ZONE OF METROPOLITAN LIMA. AN ANALYSIS OF THE \\ MANAGEMENT PROCESSES OF THE HUACA SAN BORJA CLIMA-PERÚ) BETWEEN 1986-2016
PERUSKA CHAMBI ECHEGARAY ${ }^{[\star *]}$, LUIS DONAYRE CHIUU ${ }^{[\star \star *]}$, ROSARIO GARCÍA QUISPE ${ }^{[\star \star \star \star]}$, ALDO LÉRTORA CARRERAA ${ }^{[\star * \star *)}$, WALTER SILVERA PRADO ${ }^{[\star \star \star \star * \star]}$ \\ Universidad de San Martín de Porres (Perú) \\ peruchambi@gmail.com ledchiu@gmail.com rgqgarcia@hotmail.com \\ arq.alertora@gmail.com waltersilver@hotmail.com \\ Fecha de recepción: 07 de abril de 2018 \\ Fecha de aprobación: 13 de diciembre de 2018
}

\begin{abstract}
RESUMEN
El proceso de puesta en valor del patrimonio edificado Huaca San Borja, ubicada dentro del área metropolitana de la capital del Perú, Lima, transcurrió desde 1986 al 2016. Durante estos años, los procesos de gestión iniciados a raíz de diversos convenios no cumplieron con poner en uso social y aún, continúan. Por otro lado, en el proceso no se contempló la participación de los vecinos de la huaca. A las entidades públicas y privadas que estuvieron a cargo no les comunicaron los trabajos que se realizarían ni mucho menos cómo estarían vinculados al proyecto. Esta investigación analiza los tres procesos de gestión por los que atravesó la Huaca San Borja y cómo cada uno de ellos influenció en su recuperación y puesta en valor.
\end{abstract}

\section{PALABRAS CLAVE}

Gestión del patrimonio; uso social; patrimonio arqueológico

\begin{abstract}
The process of revaluing the built heritage of the Huaca San Borja, located within the metropolitan area of the capital of Peru, Lima, ran from 1986 to 2016. During these years, the management processes initiated after various agreements did not comply with placing it into social use, and today, is still happening. On the other hand, in the process, the local neighbors' participation was not contemplated. The public and private entities that were in charge did not communicate that work would be done, much less how they would be linked to the project. This study analyzes the three management processes that the Huaca San Borja went through and how each of them influenced its recovery and revaluation.
\end{abstract}

\section{KEYWORDS}

Culture management; social use; archaeological heritage

(*) El presente artículo fue desarrollado en el marco de la investigación para el curso "Patrimonio Arqueológico" de la Maestría en Gestión Cultural, Patrimonio y Turismo de la Universidad de San Martín de Porres (USMP), dictado por el MSc. Arq. José Hayakawa Casas, en 2017.

(**) Bachiller en Comunicación Social por la Universidad de Lima (Perú). Especialidad en medios audiovisuales, Restauración y Conservación de archivos fotográficos-USA. Catedrática universitaria. Maestranda en Gestión Cultural, Patrimonio y Turismo de la USMP.

$\left.{ }^{(* * *}\right)$ Licenciado en Turismo por la Universidad de San Martín de Porres (Perú). Experiencia en guiado de museos, además en saneamiento y salubridad en Cruceros y atención al cliente en hoteles y restaurantes. Maestrando en Gestión Cultural, Patrimonio y Turismo de la USMP.

(****) Comunicadora Social por la Universidad de San Martín de Porres (Perú). Experiencia en Gestión Cultural y Prensa Institucional. Maestranda en Gestión Cultural, Patrimonio y Turismo de la USMP.

(*****) Arquitecto por la Universidad Ricardo Palma (Perú). Estudios de Doctorado Universidad Politécnica de Barcelona. Experiencia en restauración de monumentos y Catedrático universitario. Maestrando en Gestión Cultural, Patrimonio y Turismo de la USMP.

(******) Bachiller en Derecho por la Universidad Nacional Mayor de San Marcos (Perú). Experiencia en Comunicación para el Desarrollo a través de imágenes. Actualmente es fotógrafo documental. Maestrando en Gestión Cultural, Patrimonio y Turismo de la USMP. 
devenir Vol. 6, Nº11, ENERO - JUNIO 2019, PP. 107-128 - EsTUDIOS I ISSN 2312-7562 | E-ISSN 2616-4949

UNIVERSIDAD NACIONAL DE INGENIERÍA, LIMA

doi: https://doi.org/10.21754/devenir.v6i11.636

El presente artículo tiene como objetivo realizar un análisis de los diferentes procesos de gestión de la Huaca San Borja (Lima, Perú), que entre los años 1986 y 2016 ha estado a cargo de diversas instituciones públicas y privadas. Para lograrlo, se empleó el método cualitativo, utilizando como instrumentos de recolección de información las entrevistas no estructuradas a vecinos, arqueólogos, y representantes de instituciones públicas y privadas que tuvieron relación directa con la puesta en valor de la huaca, además del análisis documental de convenios, artículos de revistas y libros, entre otros.

\section{Marco de referencia}

Esta investigación está centrada en la gestión del patrimonio que en el Perú está ligado mayormente a lo arqueológico. Por tanto, resulta necesario delimitar algunos parámetros conceptuales sobre los cuales se desarrolló la investigación. Para el trabajo, se asumieron los conceptos patrimonio, y patrimonio monumental o edificado (estos dos últimos como sinónimos) en los siguientes términos:

En su sentido más amplio, el patrimonio es el conjunto de bienes heredados del pasado y, en consecuencia, el patrimonio arquitectónico puede definirse como el conjunto de bienes edificados, de cualquier naturaleza, a los que cada sociedad atribuye o en los que cada sociedad reconoce un valor cultural. Esta es una definición dinámica, pues los valores culturales son cambiantes, lo que implica que el concepto mismo de patrimonio se encuentra en permanente construcción y que los objetos que integran el patrimonio forman un conjunto abierto, susceptible de modificación y, sobre todo, de nuevas incorporaciones. (Azkarate, Ruiz de Ael \& Santana, 2003, p. 3)

En la Carta Internacional para la Gestión del Patrimonio Arqueológico (Consejo Internacional de Monumentos y Sitios, 1990), se afirma que

El Patrimonio Arqueológico representa la parte de nuestro patrimonio material para la cual los métodos de la arqueología nos proporcionan la información básica. Engloba todas las huellas de la existencia del hombre y se refiere a los lugares donde se ha practicado cualquier tipo de actividad humana, a las estructuras, vestigios abandonados de cualquier índole, tanto en la superficie, como enterrados, o bajo las aguas, así como el material relacionado con los mismos. (p. 2)

Pérez-Juez (2006) señala por su parte

La fascinación que produce el pasado perdido es un elemento que debe ser considerado en cualquier proyecto de gestión pues puede a la vez ser un aliado a favor de la promoción y divulgación del patrimonio arqueológico acondicionado, o un mecanismo de falsificación del discurso histórico. Por esa razón, es necesario valorar cómo afecta el concepto de ruina en todo este proceso. (p. 48)

En el territorio peruano, existen una gran cantidad de vestigios arqueológicos $y_{\text {, }}$ aunque hasta hoy se realizan nuevos hallazgos, resulta extremadamente complicado gestionarlos adecuadamente, recuperarlos, conservarlos y preservarlos, en suma, ponerlos en valor, considerando el trabajo mancomunado entre las autoridades y la comunidad. Como mencionan Ballart \& Tresserras (2001), "Entendemos por gestión del patrimonio, pues, al conjunto de actuaciones programadas con el objetivo de conseguir una óptima conservación de los bienes patrimoniales y un uso de esos bienes adecuado a las exigencias sociales contemporáneas" (p. 15).

Por su parte, Néstor García Canclini señala que “La selección que se preserva y la manera de hacerlo deben decidirse a través de un proceso democrático en el que intervengan los interesados y se consideren sus hábitos y opiniones" (Florescano, 1993, p. 24).

Todos estos descubrimientos arqueológicos llevaron al historiador Pablo Macera (2007) a afirmar que todo el Perú es una huaca. La acepción más contemporánea y urbana de la palabra quechua huaca o waka es "monumento arqueológico precolom- 


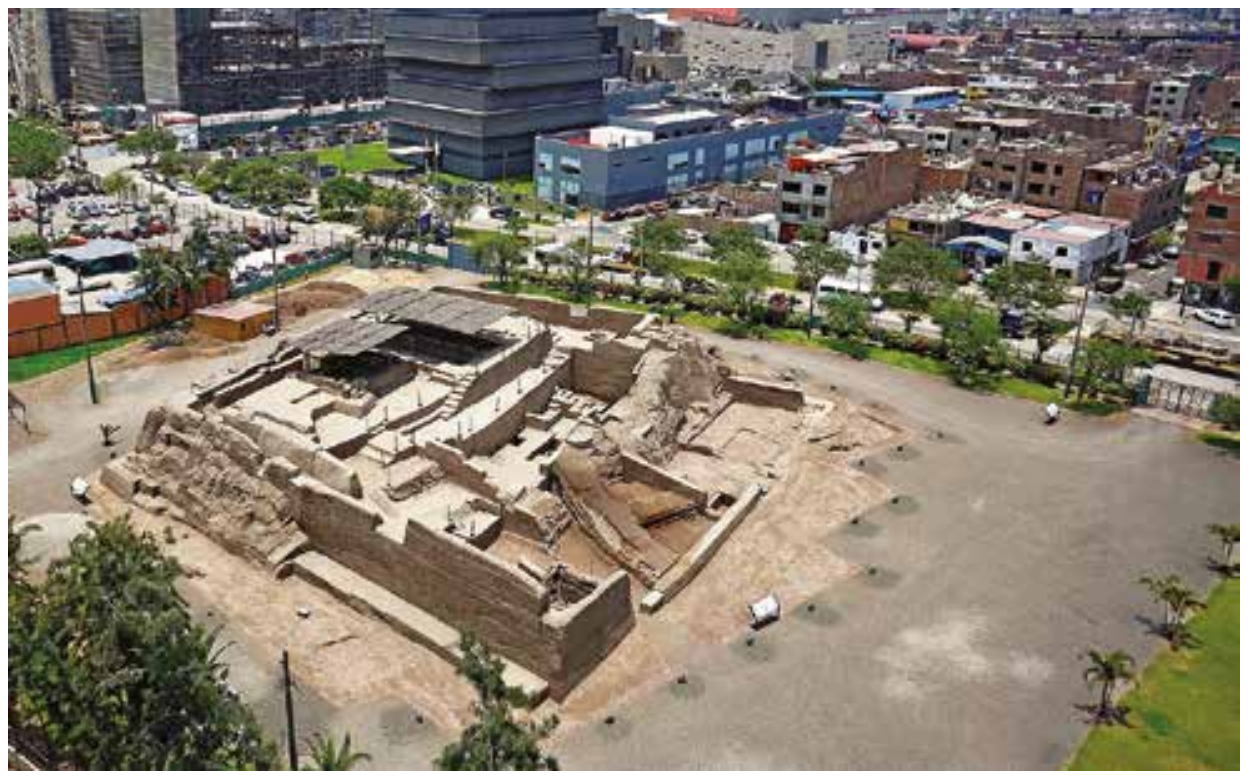

Figura 1. Panorámica aérea de la Huaca San Borja. Recuperado de https://es.wikiloc.com/rutas-a-pie/qhapaq-nan-en-el-asfalto-2-huacas-caminos-y-canales-prehispanicos-13085578/photo-8068122

bino", aunque en el ámbito de las ciencias sociales no solo se consideran las construcciones propiamente, sino que también puede tratarse de una piedra, un cerro, un río o una cueva, en tanto tuvieron carácter sagrado, tal como lo anota correctamente la Real Academia Española (2017).

Es importante mencionar, además, que en Lima Metropolitana existen 365 sitios arqueológicos o huacas que han sido declarados Patrimonio Cultural de la Nación (Municipalidad Metropolitana de Lima, 2012; Laurie, 2015). La mayoría cuenta con más de 3,500 años de antigüedad, entre ellos la Huaca Paraíso o Garagay (Ravines, 1975; Cornejo, 2013).

\section{Orígenes de la Huaca San Borja}

La Huaca San Borja se remonta a tiempos del Señorío de Ichma (Espinoza, 2014). La cultura Ichma abarcaba los valles de los ríos Rímac y Lurín, en Lima, entre los años 900 y 1470. Estos valles se abastecían de agua a través del canal de Huatica (ver Figura 1), importante canal porque hasta la actualidad los distritos de Lima, El Agustino, La Victoria, San Luis, San Borja, San Isidro, Jesús María y Lince continúan sirviéndose de él.

La cultura Ichma comprendió un conjunto importante de huacas que fueron su sede administrativa y ceremonial. Según algunas investigaciones, el curaca de Lima, Taulichusco, vivió en esta zona (Municipalidad de San Borja, 2018).

La Huaca San Borja formó parte de la cultura Ichma y perteneció a la época del Intermedio Tardío en tiempos del dominio del Señorío de Ichma. El centro de poder y religioso de esta cultura estuvo en Pachacamac y fue un tambo que funcionaba como centro de control social y político del Tahuantinsuyo. A lo largo de su historia ha sido ocupada por diversos grupos culturales:

Los Ychsma la construyeron y la usaron por aproximadamente 4 siglos, hasta la llegada de los incas alrededor del año 1432 d.C... La presencia de los incas en los complejos Ychsma no fue tan larga debido a la conquista del Tahuantinsuyo por los españoles. (Municipalidad Metropolitana de Lima, 2013, p. 28) 


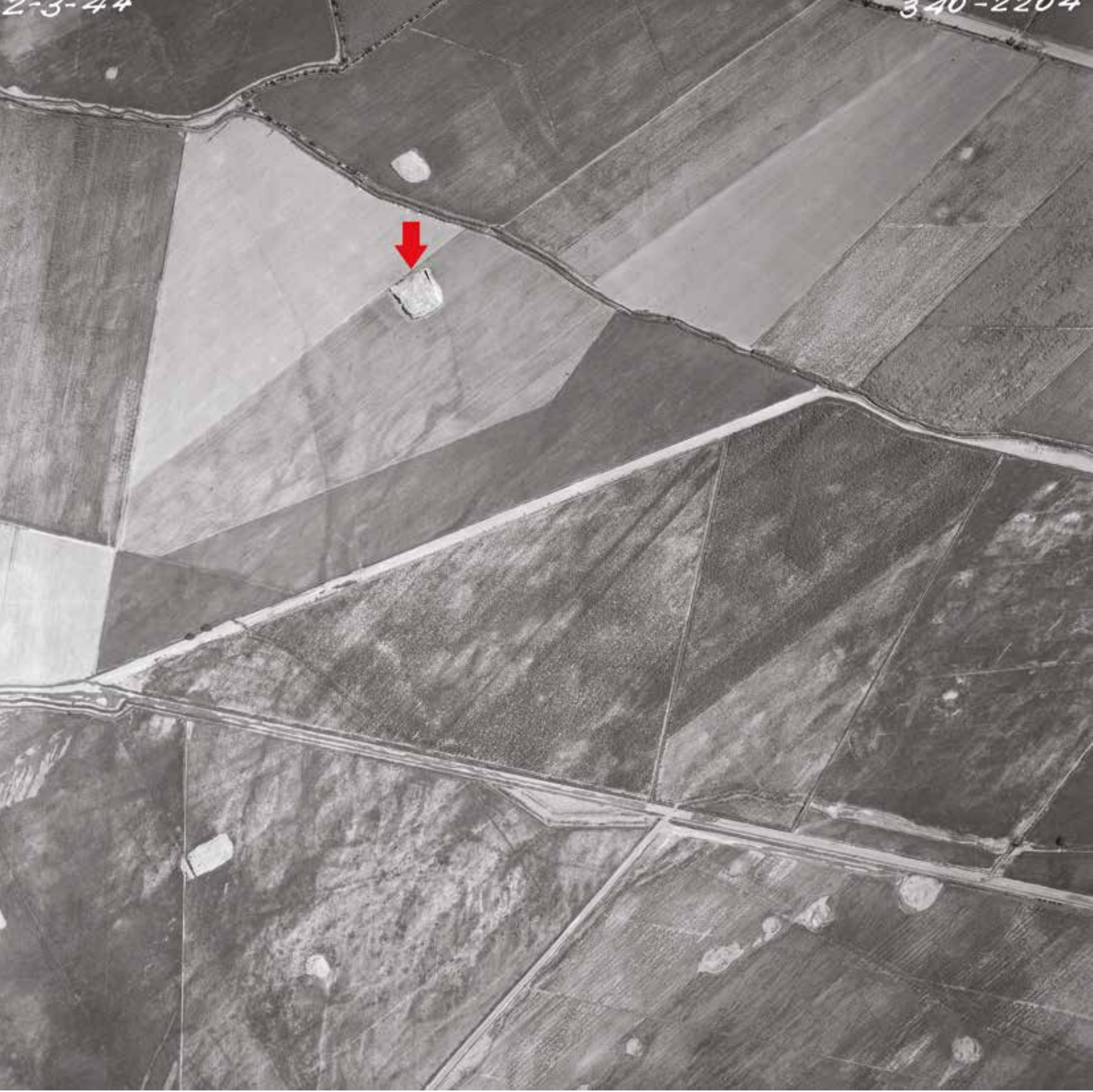

Figura 2. Foto aérea, 1944. Archivo del Servicio Aerofotográfico Nacional, 2017.
Durante el Virreinato (1542-1821) tuvo lugar el proceso de reparto de tierras a los conquistadores españoles a través de la encomienda, que consistió en que la Corona le encargaba a un individuo una cantidad determinada de indios con la obligación de adoctrinarlos en la fe católica:

Pronto, el encomendero usó su posición para adquirir algunas extensiones de tierras, las mismas que otorgarían un gran prestigio al poseedor. Poco después, la Corona otorgaría mercedes de tierra en forma oficial, formándose haciendas y estancias en todo el Virreinato. Lima no fue la excepción y sus valles se vieron poblados de numerosas haciendas, muchas de ellas en ma- 
devenir Vol. 6, Nº11, ENERO - JUNIO 2019, PP. 107-128 - ESTUDIOS I ISSN 2312-7562 | E-ISSN 2616-4949

UNIVERSIDAD NACIONAL DE INGENIERÍA, LIMA

doi: https://doi.org/10.21754/devenir.v6i11.636
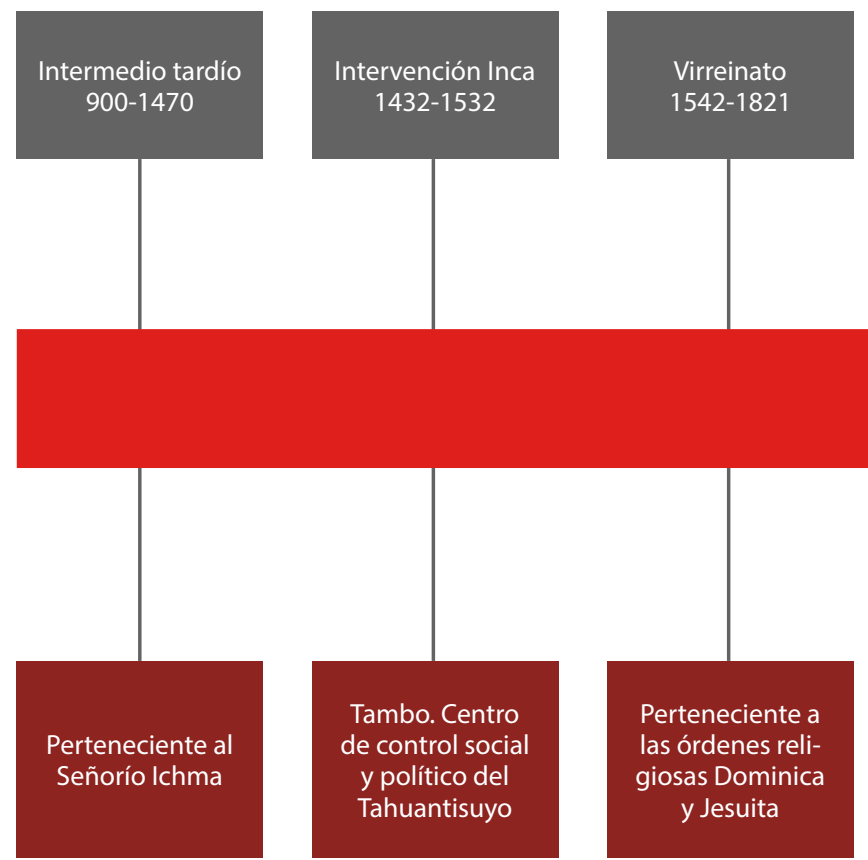

República

1821 hasta la actualidad

Figura 4. Proceso histórico de la Huaca San Borja desde sus inicios hasta la actualidad. Elaboración propia sobre la base de información extraída de diversas fuentes, 2018.

el costo de 40,000 pesos más por 45 esclavos y 10 viejos, aperos, fábrica y otros. (Vegas de Cáceres, 1996, p. 86)

En la investigación Patrimonio Turístico del Distrito de San Borja, por el Instituto de Investigación de la Universidad de San Martín de Porres (1993), se añade lo siguiente:

En 1593 la Hacienda Limatambo tenía 357 fanegadas, de ella 14 fanegadas - 52 hectáreas, eran Huacas. Hacia 1746 un juicio por aguas entre propietarios de Limatambo con 'los Jesuitas dueños de la Hacienda San Borja' ratifica un proceso continuado de división de la propiedad territorial agrícola en el transcurso del tiempo, después de la expulsión de los Jesuitas, se registra hacia 1794 una venta de parte de la Hacienda Limatambo al propietario de la Hacienda San Borja, entonces don Cayetano Fernández Maldonado quien por ese medio anexó a su propiedad 11 fanegadas de tierra perteneciente a Limatambo. (p. 14)

En Lima, durante la República, se inició un proceso de urbanización en la periferia del Centro Histórico, en los terrenos que ocupaban las mencionadas haciendas del valle de Lima, y se crearon los distritos que actualmente conforman la ciudad (ver Figuras 3 y 4) desde el año 1821 hasta la actualidad.

Es importante mencionar también que las referencias y la bibliografía sobre la Huaca San Borja son muy escasas. No se cuenta con datos escritos hasta después de 1986, aunque sí había sido previamente inventariada por diversos organismos, como la Junta Deliberante Metropolitana de Monumentos Históricos, Artísticos y Lugares Arqueológicos de Lima, en 1962-1963 y el Inventario de Monumentos Arqueológicos del Perú, en 1985 (p. 68). A partir de su primera intervención en 1986, la huaca hace su aparición en el mundo académico a través de la revista Arqueología y Sociedad número 31, editada por el Museo de Arqueología y Antropología de la Universidad Nacional Mayor de San Marcos (UNMSM), con el artículo titulado "Excavaciones y Estudios Etnohistóricos del Monumento Arqueológico San Borja Norte, Valle de Lima".

Actualmente, la Huaca San Borja se encuentra en el interior de una megalópolis de casi 10 millones de habitantes (Instituto Nacional de Estadística e Informática, 2018), espe- 


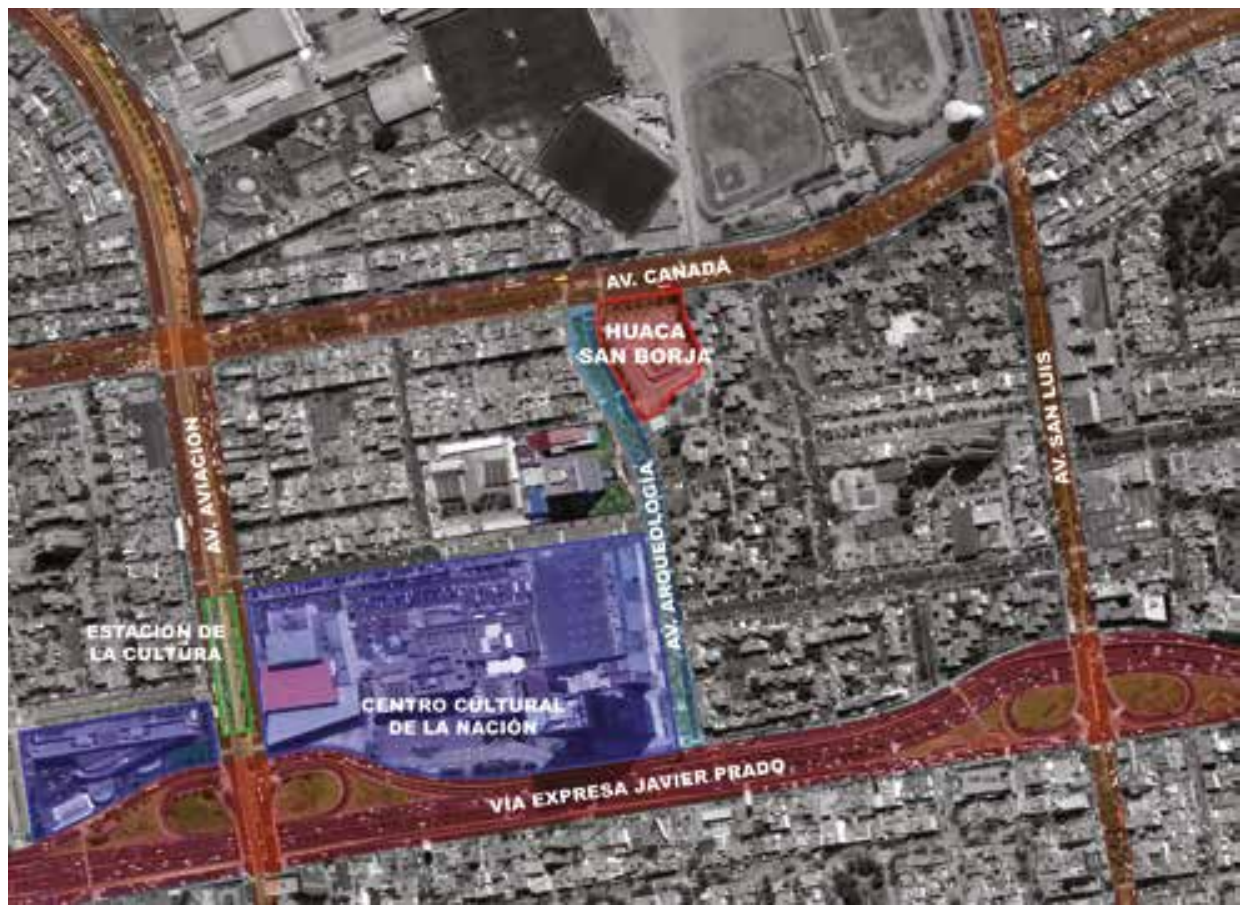

Figura 5. Emplazamiento urbano de la Huaca San Borja. Elaboración propia, 2017.

cíficamente en el distrito del mismo nombre, uno de los 43 distritos que componen la Provincia de Lima. Forma parte de un eje cultural al estar ubicada a poca distancia del Gran Teatro Nacional, el Ministerio de Cultura, la Biblioteca Nacional del Perú, el Ministerio de Educación y el Centro de Convenciones de Lima (ver Figura 5).

En cuanto al uso del suelo, el monumento arqueológico está inmerso en una zona predominantemente residencial, ubicado al costado del Conjunto Habitacional “Torres de San Borja", a su vez comprendido entre los hitos urbanos de relevancia metropolitana y nacional, así como centros educativos y financieros. Sin embargo, la dinámica entre el monumento y su entorno urbano es nula. No existe una integración e interacción espacial a través de las áreas de amortiguamiento que logren llamar la atención de los transeúntes, residentes o trabajadores al recorrer el recinto patrimonial (ver Figuras 6, 7 y 8 ).

\section{La Experiencia de gestión de la Huaca San Borja}

La Huaca San Borja ha atravesado tres procesos de gestión desde 1986, año en que surgieron las primeras iniciativas para recuperarla. Hasta ese entonces, estuvo abandonada y era considerada un lugar peligroso por los vecinos y transeúntes, quienes desconocían su valor patrimonial. Precisamente por tratarse de un lugar oscuro y abandonado, era utilizado como botadero de basura, donde habitaba gente de mal vivir.

Ninguna autoridad había puesto sus ojos sobre ella, teniendo en cuenta que el patrimonio arqueológico conecta a las personas con su pasado, pues aporta nociones sobre quiénes son y de dónde vienen, por lo que conservarlo es también mantener viva la memoria de un país.

\section{Gestión 1986-2000}

La primera iniciativa por recuperar la Huaca San Borja para el uso social provino de la Municipalidad de San Borja. Hasta los años 70 del siglo pasado, la zona era parte de los terrenos agrícolas que rodeaban Lima; solo unos montículos de variable elevación hacían notoria la presencia de restos arqueológicos. 
devenir Vol. 6, №11, ENERO - JUNIO 2019, PP. 107-128 - EstudIOS I ISSN 2312-7562 | E-ISSN 2616-4949

UnIVERSIDAD NACIONAL DE INGENIERÍA, LIMA

doi: https://doi.org/10.21754/devenir.v6i11.636

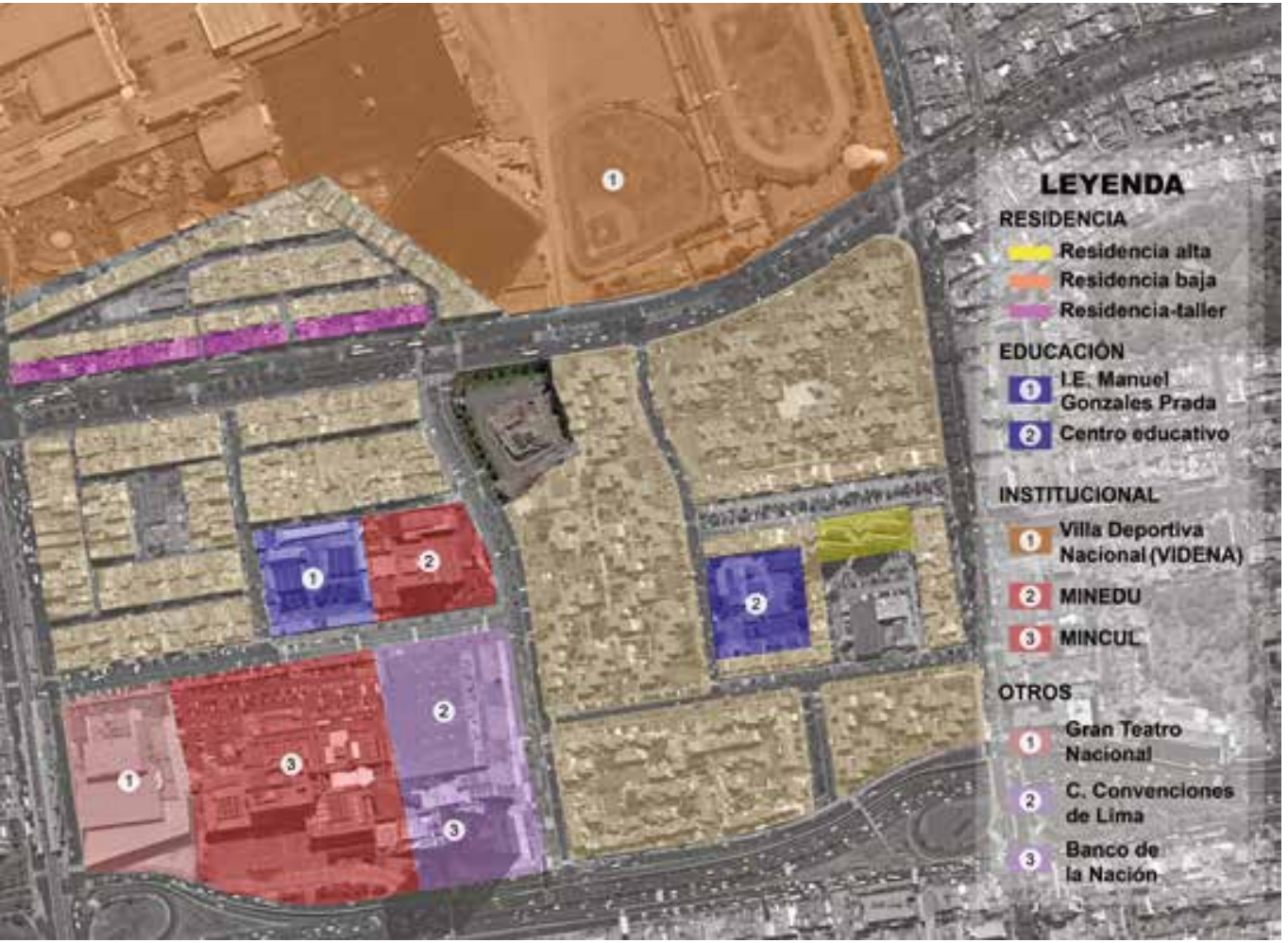

Figura 6. Usos predominantes del entorno. Elaboración propia, 2017

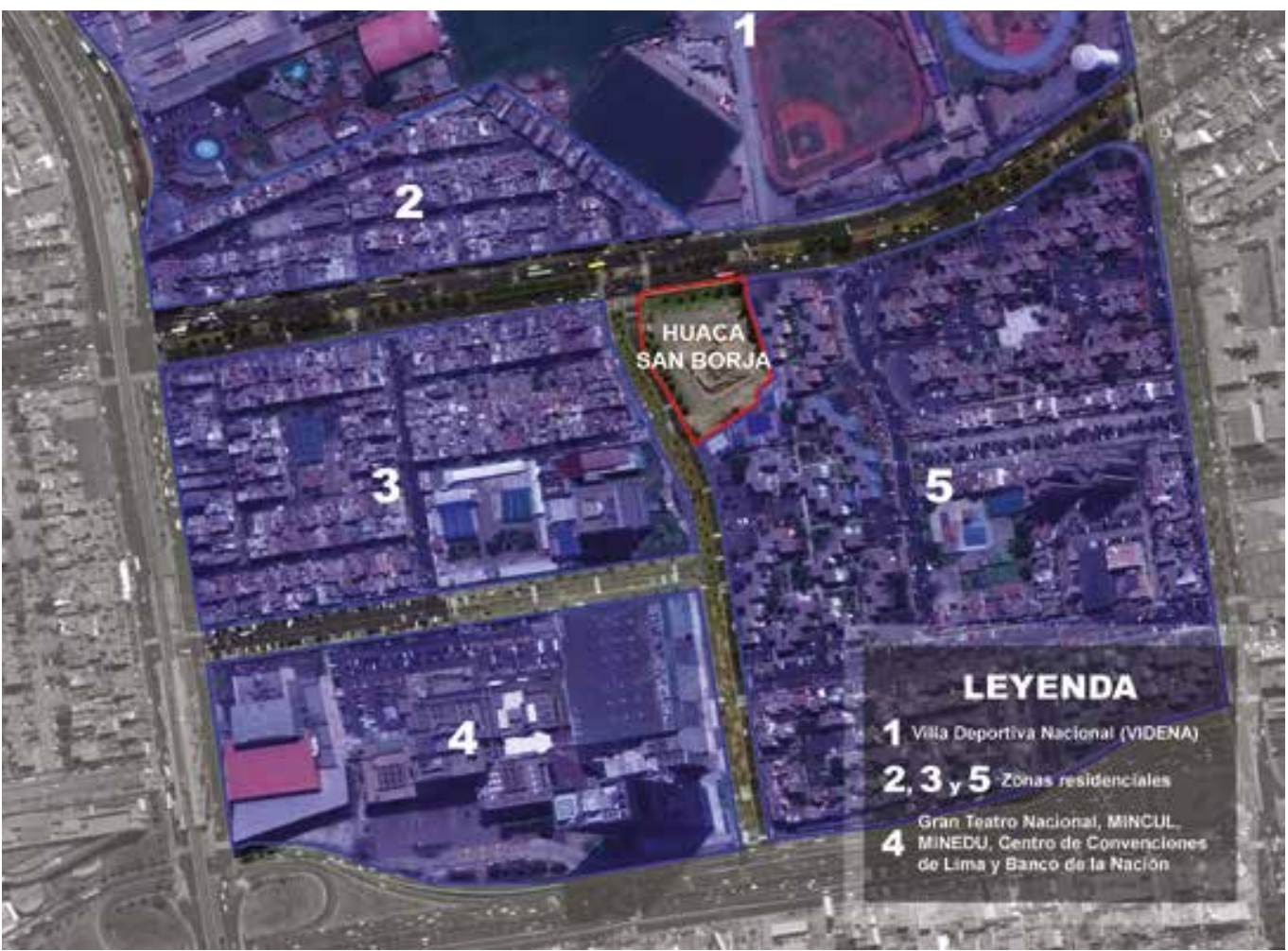

Figura 7. Áreas diferenciadas alrededor de la Huaca San Borja. Elaboración propia, 2017. 


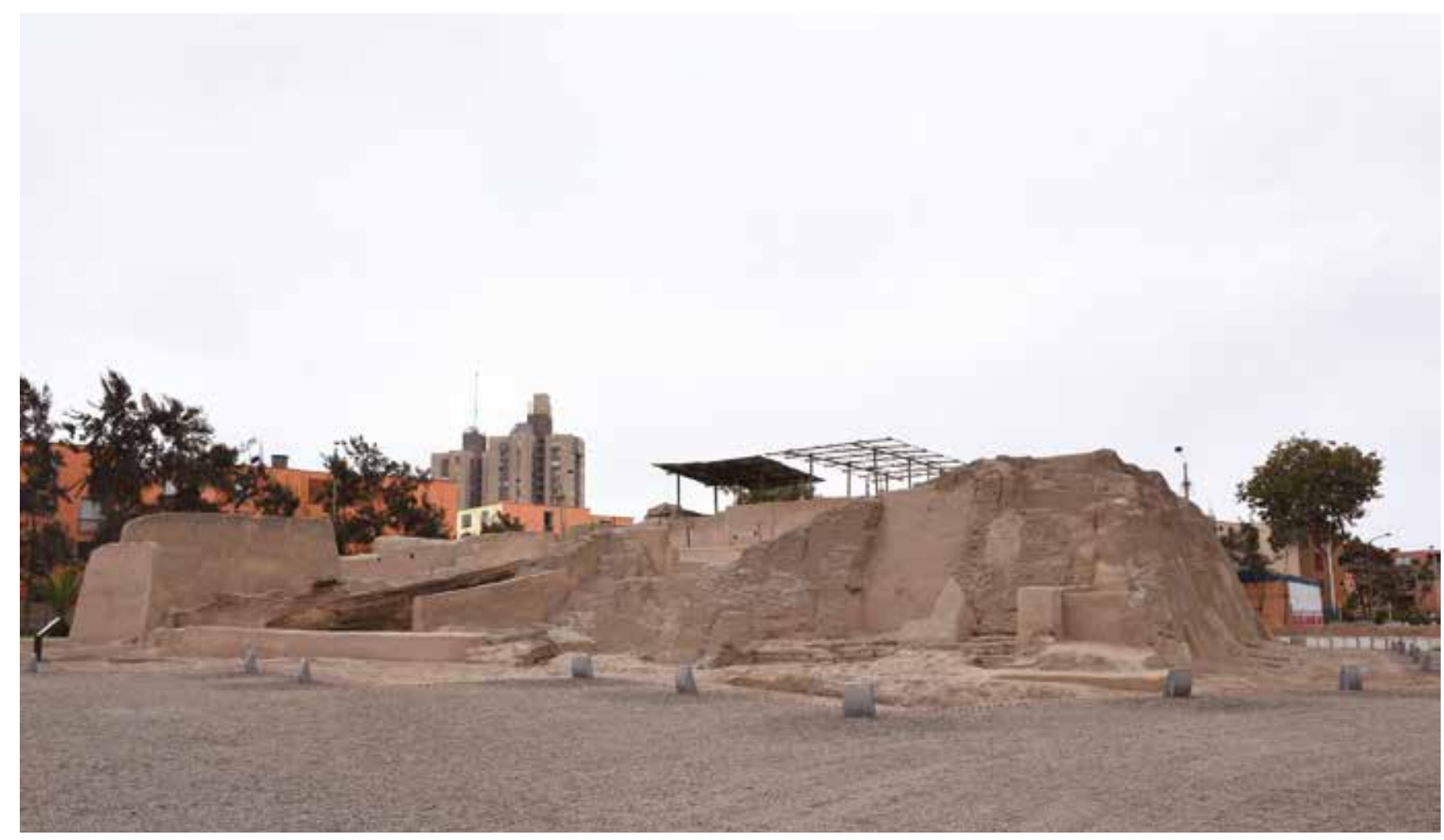

Figura 8. Huaca San Borja. Archivo fotográfico personal de P. Chambi, 2017.

Durante el segundo gobierno del arquitecto Fernando Belaúnde (1980-1985), la Empresa Nacional de Edificaciones desarrolló el proyecto Conjunto Torres de San Borja (ver Figura 9), con lo que la huaca quedó atrapada entre la av. Canadá, la nueva obra, el Ministerio de Pesquería y el asentamiento humano San Juan Bautista.

El arqueólogo Bueno (2016, p. 424) hace referencia que las compañías constructoras contratistas, encargadas de la construcción del conjunto habitacional, amontonaban los escombros en la huaca y que, al finalizar las obras, estos cubrieron al monumento por tres de sus lados.

No tardaron en aparecer ocupantes precarios en las inmediaciones. Hacia el año 1986, el municipio de San Borja desalojó a estos invasores y procedió a limpiar el lugar, liberándolo de toneladas de desechos. Según manifiesta el arqueólogo Alberto Bueno Mendoza, la Municipalidad de San Borja tenía un proyecto para hacer un centro cultural en la zona de la huaca (ver Figura 10). Para llevarlo a cabo, se había oficiado al Instituto Nacional de Cultura (INC) que se encargue de los trabajos arqueológicos, pero el presupuesto era muy elevado y desanimó a las autoridades municipales. El arqueólogo Bueno al ser informado por el INC sobre la situación de la huaca y de la intención del municipio de intervenir en ella planteó una nueva alternativa: un convenio bilateral. Como profesor de la Universidad de Lima (UL), llevó la propuesta a las autoridades de la Facultad de Humanidades, quienes autorizaron, a nombre de la universidad, realizar las coordinaciones con el municipio.

Es así como el alcalde de ese entonces, el Sr. Hugo Sánchez Solari, aceptó el convenio para la ejecución del proyecto y tomó las acciones pertinentes para recuperar la huaca. El Convenio de Cooperación Cultural entre la Municipalidad de San Borja, representa- 
devenir Vol. 6, №11, ENERO - JUNIO 2019, PP. 107-128 - ESTUdIOS I ISSN 2312-7562 | E-ISSN 2616-4949

UnIVERSIDAD NACIONAL DE INGENIERÍA, LIMA

doi: https://doi.org/10.21754/devenir.v6i11.636

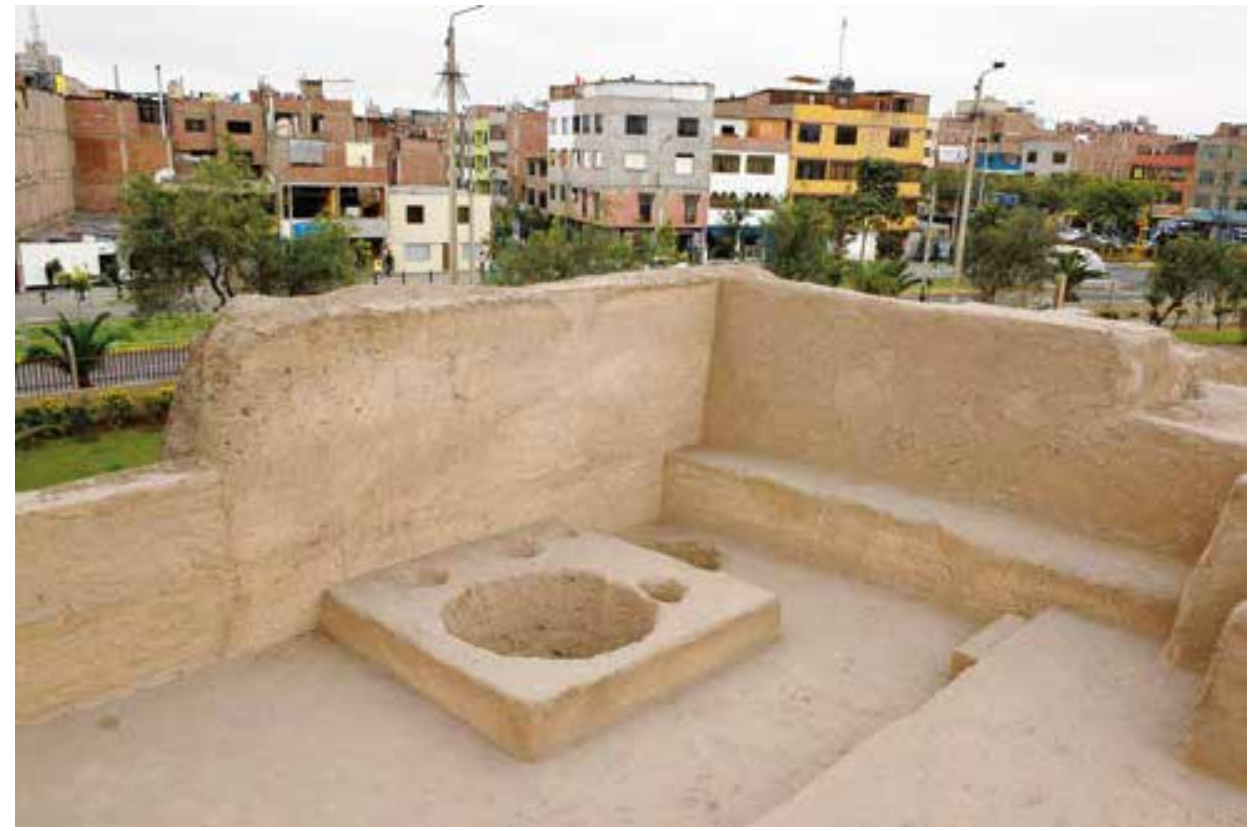

Figura 9. Entorno urbano, vivienda y comercio informal. Archivo fotográfico personal de P. Chambi, 2017.

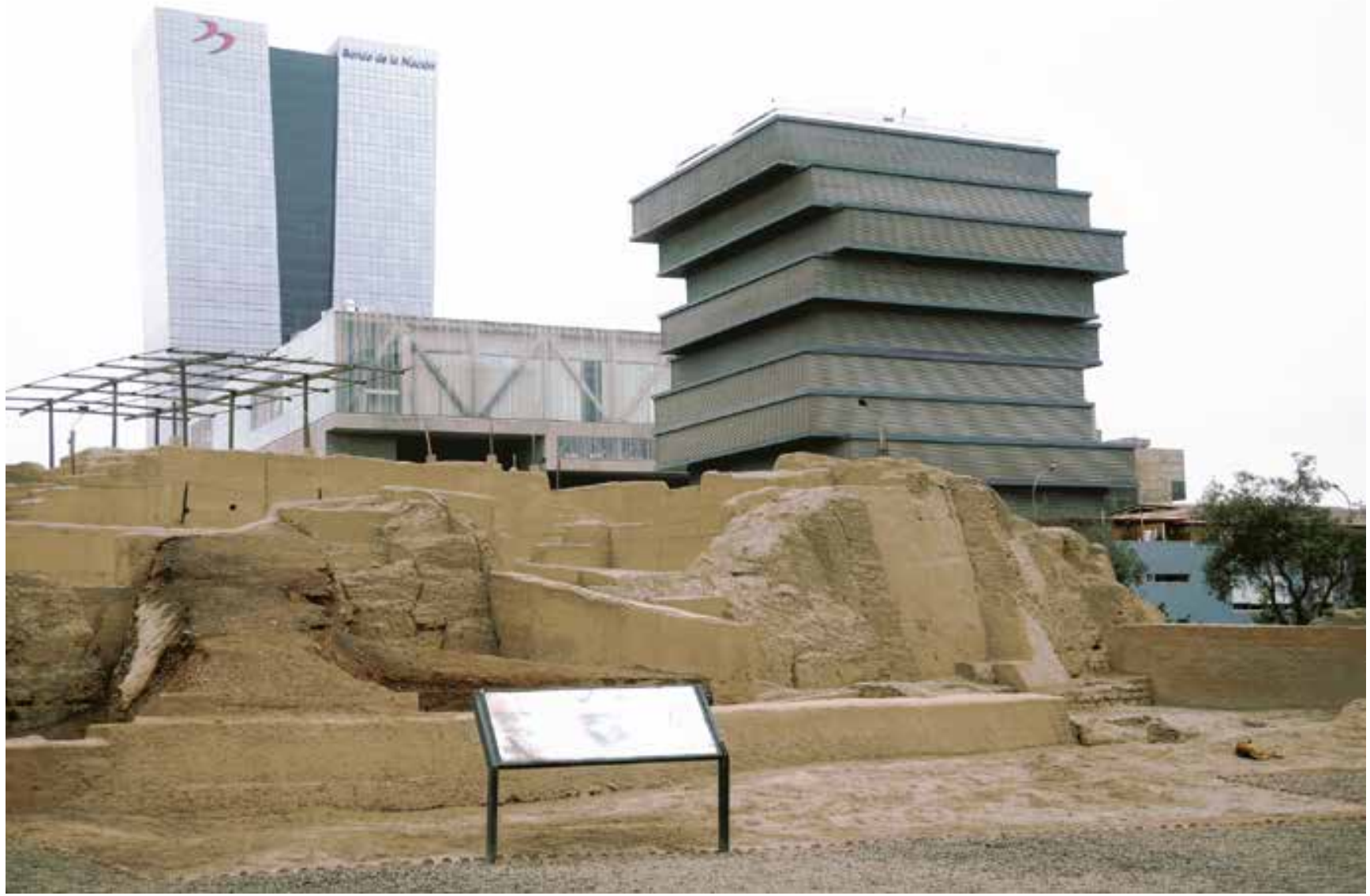

Figura 10: Entorno urbano institucional. Archivo fotográfico personal de W. Silvera, 2017. 
do por el alcalde, y la rectora de la UL, Dra. Ilse Wisotzky, se firmó en la sede del municipio el 10 de diciembre de 1987.

Desde fines de 1986, con el aval de la UL, el arqueólogo Alberto Bueno había redactado el proyecto, que venía gestionando en el INC. Allí pedía un permiso para realizar trabajos de prospección y excavación. La autorización formal fue publicada en el diario oficial El Peruano el 17 de diciembre de 1987, mediante Resolución Suprema №34687-ED, que autoriza al arqueólogo Bueno Mendoza y a las instituciones involucradas a ejecutar las obras solicitadas.

Los trabajos se iniciaron con una investigación de fuentes etnohistóricas y otros documentos que pudieran dar luces sobre el lugar. Hasta la actualidad, la información y los datos al respecto siguen siendo escasos.

El arqueólogo Alberto Bueno (2016) señala que las acciones se desarrollaron de acuerdo al plan concertado con el INC, la UL y la Municipalidad de San Borja, por lo que es posible deducir que existía un plan para la excavación, puesta en valor y uso de la huaca, aunque al parecer cada institución involucrada tenía un interés particular.

Bueno Mendoza (2016) precisa, en su artículo "Excavaciones y Estudios Etnohistóricos del Monumento Arqueológico San Borja Norte, Valle de Lima", publicado en la revista Arqueología y Sociedad, las acciones que se desarrollaron como parte del plan concertado:

1. Presentación de documentos para tramitar la adquisición de equipo, herramientas, instrumentos y artículos para trabajo de campo. La Municipalidad adquirió las provisiones según lista presentada.

2. Trámites en la Municipalidad para construcción del campamento, que consta de los siguientes ambientes: caseta de vigilancia y guardianía, galpón para herramientas y depósito de materiales, gabinete de estudios y administración. En el mes de julio de 1988 se terminó de construir la caseta, según el plano coordinado con la Alcaldía y tramitado en la sección Abastecimientos del Consejo.

3. Los problemas económicos nacionales atrasaron e hicieron lentos los trámites para ultimar los preparativos y convocar al personal para los trabajos. Las dificultades se superaron en el mes de agosto (1988).

4. Durante los meses de julio y agosto, la Universidad de Lima financió el trabajo de topografía realizado por el especialista de la Universidad Agraria (CIZA), Bernardino Ojeda, conjuntamente con nuestra asistencia, coordinación y supervisión.

5. El plano topográfico permite acotar en área la excavación arqueológica, pasar a la cuadriculación respectiva y plantear la estrategia de roturación del suelo.

6. El arqueólogo Anselmo Lozano Calderón ingresó a trabajar en agosto como jefe de campo; con su concurso hemos procedido a metrar el área por sectores y cuadrículas en aplicación de la planificación de las excavaciones.

7. La convocatoria para el personal de obreros se cumplió entre fines de agosto y comienzos de septiembre, los cuales realizan trabajos de limpieza y escombramiento de superficie. Restos de escombros de construcción, basura, deyecciones humanas acumuladas sobre el monumento y trastos de covachas ocupadas por vagos sumaban alrededor de cinco toneladas de desperdicios para erradicar. (pp. 425-426)

Los resultados del trabajo arqueológico realizado en 1990 fueron exitosos para la UL y la Municipalidad de San Borja. Tras esa experiencia, en "atención a la calidad de la arquitectura monumental descubierta, el cumplimiento de los objetivos propuestos y los efectos multiplicadores y exitosos para ambas instituciones firmantes del Conve- 
devenir Vol. 6, Nº11, ENERO - JUNIO 2019, PP. 107-128 - EsTUDIOS I ISSN 2312-7562 | E-ISSN 2616-4949

UNIVERSIDAD NACIONAL DE INGENIERÍA, LIMA

doi: https://doi.org/10.21754/devenir.v6i11.636

nio de Cooperación Cultural" (Bueno Mendoza, 2016), ambas instituciones firmaron un segundo convenio para extender su cooperación durante 1990 y 1991. Finalmente, el acuerdo se extendió hasta el año 1993.

Durante ese periodo, no se le otorgó importancia a la participación de la población circundante; todo indica que el trabajo desarrollado en la huaca tenía principalmente fines académicos y solo el municipio estaba interesado en el centro cultural. Con las excavaciones, quedó claro que se trataba de una construcción menor que tuvo un uso religioso y administrativo ligado al agua.

En el artículo "Complejo Arqueológico Huaca San Borja, Ejemplo de Recuperación", publicado en la revista Gaceta Cultural, el arqueólogo Carlos Rea (2007) manifiesta que el convenio entre la Municipalidad de San Borja, la UL y el INC se realizó con el siguiente objetivo:

...crear condiciones para la creación de un nuevo espacio de cultura viva, donde puedan difundirse los valores y sirva de marco para el desarrollo de actividades culturales y artísticas interinstitucionales. Paralelamente a los trabajos arqueológicos y de conservación se desarrolló una propuesta que permitiera su inserción a la comunidad. (p. 21)

En este caso, la primera etapa de la gestión no contó con un plan de gestión institucional, sino que operó de acuerdo a objetivos bastante generales, pero de facto se presentó como la iniciativa de un académico, el arqueólogo Alberto Bueno, quien probablemente aprovechó sus conexiones como docente de la UNMSM y la UL para convencer a las autoridades de la recién creada Municipalidad de San Borja de desarrollar este proyecto de intervención.

Podría decirse que se trata de un proyecto caudillista en el cual, a falta de planificación estatal o académica, un arqueólogo tomó la iniciativa de intervenir. Además, es necesario mencionar que el periodo comprendido entre 1985 y 1990 fue el peor de toda la vida republicana del Perú en materia económica e institucional. Es un hecho de que esta situación jugó un papel fundamental en el destino de la Huaca San Borja.

Resulta crucial preguntarse si la crisis económica e institucional que atravesaba el Perú es justificación suficiente para la falta de un plan de gestión que considere la intervención y el correcto manejo del patrimonio arqueológico. Este caso de estudio permite indagar sobre qué tan importante era para el Estado y para las instituciones académicas de esa época efectuar un trabajo planificado y orgánico institucionalmente.

Estas son preguntas que desbordan el alcance de esta investigación, pero es necesario encontrarles una respuesta para comprender la política cultural y el manejo estatal durante ese periodo. Lo único que queda claro es que el modelo de gestión, en el caso de la Huaca San Borja, fue el del caudillo que dirige el proyecto según su parecer y su buen juicio.

Entre 1994 y el año 2000, se abandonan las obras en la huaca y solo quedaron dos guardianes. El tiempo y el abandono hicieron su trabajo: el área volvió a llenarse de basura y desmonte, y nuevamente estaba habitada por gente de mal vivir.

\section{Administración de la Huaca San Borja}

Según estaba estipulado en el convenio, la administración del proyecto recayó sobre el arqueólogo Alberto Bueno, quien también estaba encargado de la dirección técnica del proyecto. Su trabajo no solo era coordinar y supervisar los trabajos, sino también gestionar con el municipio.

La iniciativa de Bueno probablemente iba más allá de los planes originalmente trazados. Por ejemplo, incluyó la participación de estudiantes de la UNMSM al comienzo de 


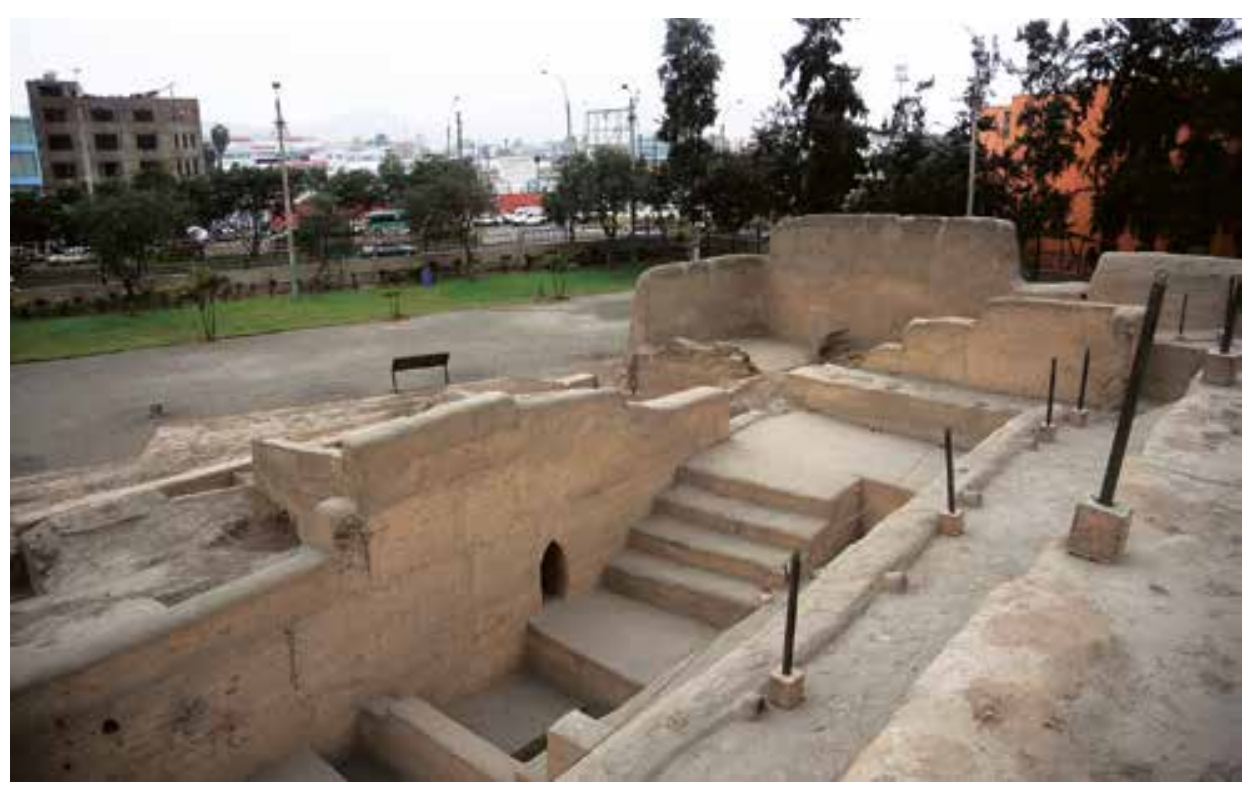

Figura 11. Huaca San Borja, con frente a la av. Canadá. Archivo fotográfico personal de W. Silvera, 2017.

los trabajos, quienes posiblemente eran sus alumnos, aunque no es posible asegurar si desde el inicio de los planes se contemplaba su apoyo en la ejecución de las obras.

La remuneración del personal especializado (arqueólogos y topógrafos) fue cubierta por la UL, mientras que los pagos destinados a operarios, como la construcción del campamento y las herramientas empleadas estuvieron a cargo de la Municipalidad de San Borja.

En este primer proceso de gestión, no se consideró la intervención de los vecinos de la huaca, quienes solo fueron sujetos pasivos de los planes desarrollados. El exdirigente vecinal de las Torres de San Borja, Víctor Piscoya (comunicación personal 30 de agosto de 2017), menciona que el Instituto Nacional de Cultura era una isla y no tenían acercamiento con los vecinos, quienes consideraban a la huaca como un cerrito. Además, refiere que hasta la fecha siguen quejándose por las construcciones y que han convertido a la huaca en una fábrica de ladrillos donde botan sus desperdicios. Por este motivo, es importante considerar la participación de los vecinos en todo proceso de puesta en valor, como señala Amalia Pérez-Juez (2006) “La sensibilización es el único camino para conseguir la protección, conservación y trasmisión del patrimonio arqueológico" (p. 283).

\section{Gestión 2000-2011}

Culminado el convenio en 1993, se paralizaron las obras hasta el año 2000. Durante este periodo, no se realizó ningún trabajo de recuperación, los motivos son inciertos. Como consecuencia la huaca volvió a llenarse de basura y los guardianes que trabajaron allí en el periodo 1986-1993 pasaron a ser ocupantes precarios.

En 2000 la huaca fue incluida en un plan de intervención del Museo de la Nación. Esta nueva institución fue creada en el gobierno de Alan García, en 1988. En un comienzo, fue un organismo público descentralizado del Sector Educación, situación que se mantuvo hasta el 14 de octubre de 1992, cuando el entonces presidente Alberto Fujimori dispuso su incorporación al INC. En el año 2000, el Museo de la Nación empezó las intervenciones en la Huaca San Borja.

Bajo el nombre Proyecto Institucional de Investigación Arqueológica y Puesta en Valor Huaca San Borja, el arqueólogo Carlos Rea intervino en la huaca por encargo de la 
devenir Vol. 6, Nº11, ENERO - JUNIO 2019, PP. 107-128 - EstudIOS | ISSN 2312-7562 | E-ISSN 2616-4949

UNIVERSIDAD NACIONAL DE INGENIERÍ, LIMA

doi: https://doi.org/10.21754/devenir.v6i11.636

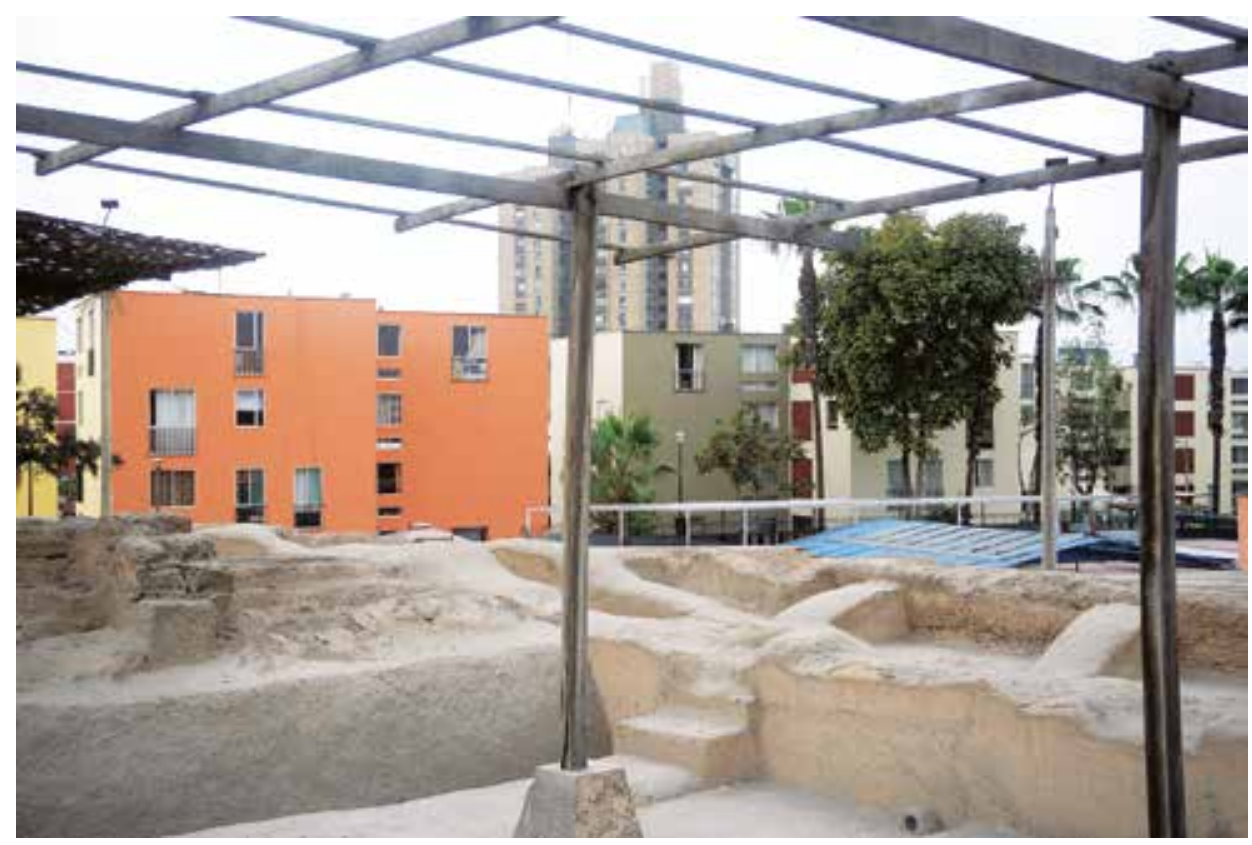

Figura 12. Entorno urbano, vivienda planificada. Archivo fotográfico personal de W. Silvera, 2017.

Dirección de Investigación del Museo de la Nación, a cargo de las gestiones administrativas. Rea afirma que, al entrar a la huaca, en el año 2000, encontró al monumento muy dañado (ver Figura 11):

La problemática era desastrosa, los consumidores de drogas habían hecho su recinto en el área de la huaca; las dos familias que empezaron como guardianes en la primera etapa del trabajo ahora eran ocupantes precarios y tenían pretensiones de quedarse. La zona era merodeada por gente afín al gobierno de Alan García, que se había especializado en invasiones de espacios públicos, por esa misma razón, los vecinos de la zona aledaña denominada Asentamiento Humano San Juan Macías se había divido y ahora compartía espacio con la cooperativa de vivienda San Juan Masías. Todo indicaba que la zona necesitaba una urgente intervención. La estrategia para desalojar a los ocupantes precarios fue tolerarlos durante el primer momento de intervención y cuando estaba consolidado el trabajo, se les persuadió para que se retiraran, no hubo uso de fuerza o acciones legales. (Comunicación personal, 25 de agosto de 2017)

La primera medida que se tomó estuvo orientada a garantizar la estabilidad estructural del monumento. En primer lugar, se gestionó con la Universidad Nacional de Ingeniería (UNI), específicamente la Facultad de Ingeniería Civil Estructural, la realización de un análisis de espectrometría. Alumnos del último año realizaron pruebas de resistencia de suelos y el trabajo no tuvo costo, pues fue parte de la gestión que a título personal hizo Carlos Rea. Los trabajos llevados a cabo para asegurar la estabilidad consistieron en rellenar uno de los lados de la huaca, a manera de rampa.

Esa primera etapa del proyecto fue desarrollada por un equipo conformado por un director, un codirector, tres arqueólogos, dos estudiantes de arqueología y cuatro obreros. Se trabajó con ese personal por un espacio de tres años. Para los trabajos de conservación, se buscó el apoyo de la Universidad Federico Villarreal, también por iniciativa de Rea.

Colindan con la huaca las Torres de San Borja (ver Figura 12), al asentamiento humano San Juan Macías y la cooperativa de vivienda del mismo nombre. Estos últimos están conformados por migrantes provenientes de otras provincias, que, según Rea, están más acostumbrados a ver huacas de piedra que de adobe y tierra, razón por la cual calificaban a la huaca como cerrito. 


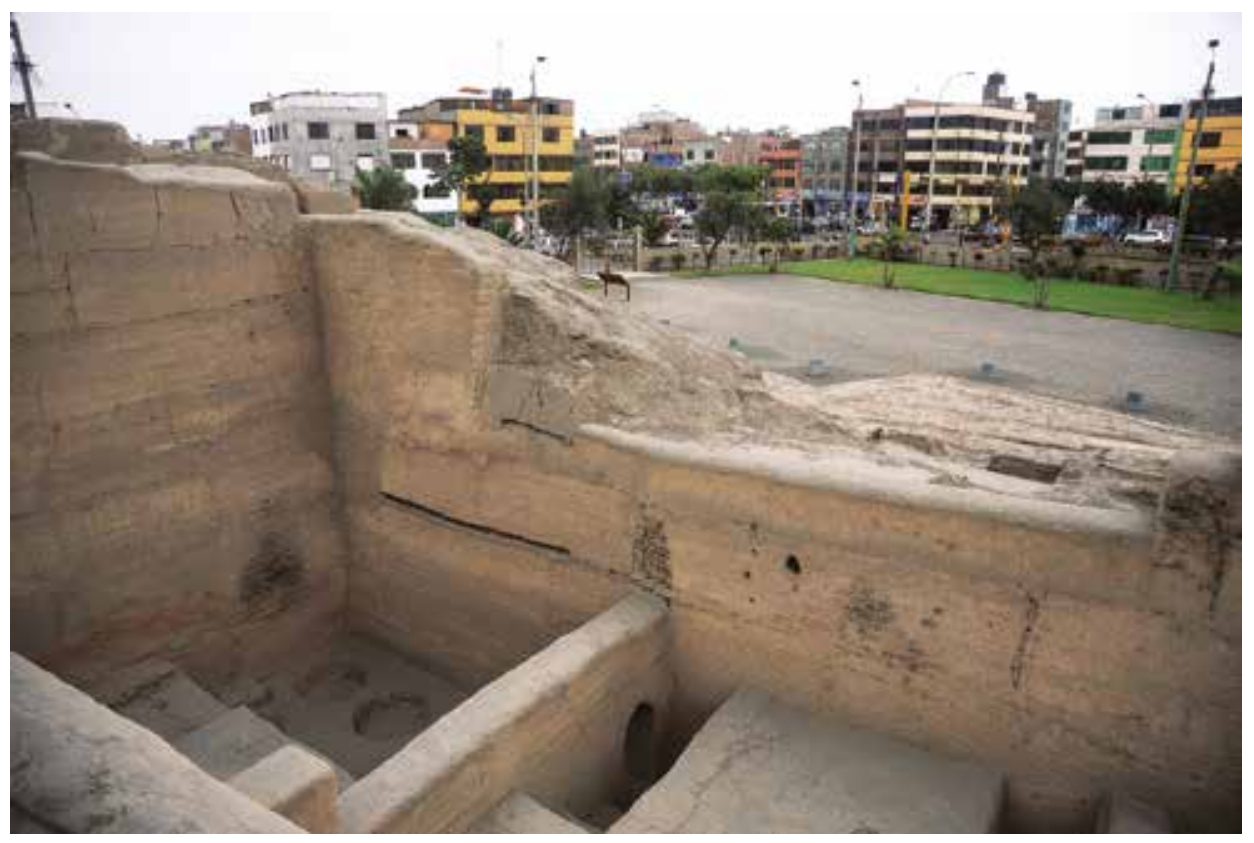

Figura 13. Entorno con notorio desorden urbano. Archivo fotográfico personal de W. Silvera, 2017.

Rea buscó la asistencia del Taller Interdisciplinario de Ciencias Sociales (TICS) de la UNMSM, conformado por antropólogos y sociólogos, quienes se encargaron de diseñar y organizar un estudio de impacto ambiental, y de llevar a cabo un trabajo de sensibilización con los vecinos, lo cual permitió obtener mejores resultados, especialmente con la población del asentamiento humano y la cooperativa de vivienda (ver Figura 13). El TICS desarrolló la idea de que es un privilegio vivir al lado de un patrimonio monumental protegido por el Estado. Se estableció como meta mínima que los vecinos no echaran basura en el área de la huaca. Esta labor fue realizada durante el periodo 2000-2001; gracias a ello, la fisonomía del lugar cambió radicalmente y se logró generar respeto hacia el lugar, aunque aún no haya sido asumido como propio.

Debido a que la zona donde está ubicada la Huaca San Borja es el núcleo cultural del Perú, el Museo de la Nación generó una propuesta para integrarla a través de un paseo peatonal, con la finalidad de que todas las visitas al museo terminen en la huaca. La idea también caló en el gobierno distrital, que comenzó a trabajar en la recuperación de los jardines circundantes al recinto.

En el 2011, la Huaca San Borja fue una de las 10 huacas elegidas en todo el Perú por el Plan COPESCO (Unidad Ejecutora del Ministerio de Comercio Exterior y Turismo), para ser dotada de acondicionamiento nocturno (Hidalgo, 2011). El financiamiento también consideraba un pequeño museo, servicios higiénicos, señalización y paneles informativos. Sin embargo, el Plan COPESCO no pudo entregar las obras, debido a algunas deficiencias, que fueron señaladas por las autoridades del Museo de la Nación:

- Carteles deteriorados, debido a que se usó micas de mala calidad y las estructuras metálicas que los sostienen ya se encuentran oxidadas (ver Figura 14).

- Reflectores que no funcionan, además se han colocado unas estructuras de metal -como estacas- para evitar el robo de estas, desentonando con el monumento en general.

- No se terminó de acondicionar el museo.

- Como observación adicional, el Consejo Nacional para la Integración de la Persona con Discapacidad recomendó cambiar el piso de gravilla por tierra apisonada. 
devenir Vol. 6, Nº11, ENERO - JUNIO 2019, PP. 107-128 - ESTUDIOS I ISSN 2312-7562 | E-ISSN 2616-4949

UNIVERSIDAD NACIONAL DE INGENIERÍ, LIMA

doi: https://doi.org/10.21754/devenir.v6i11.636

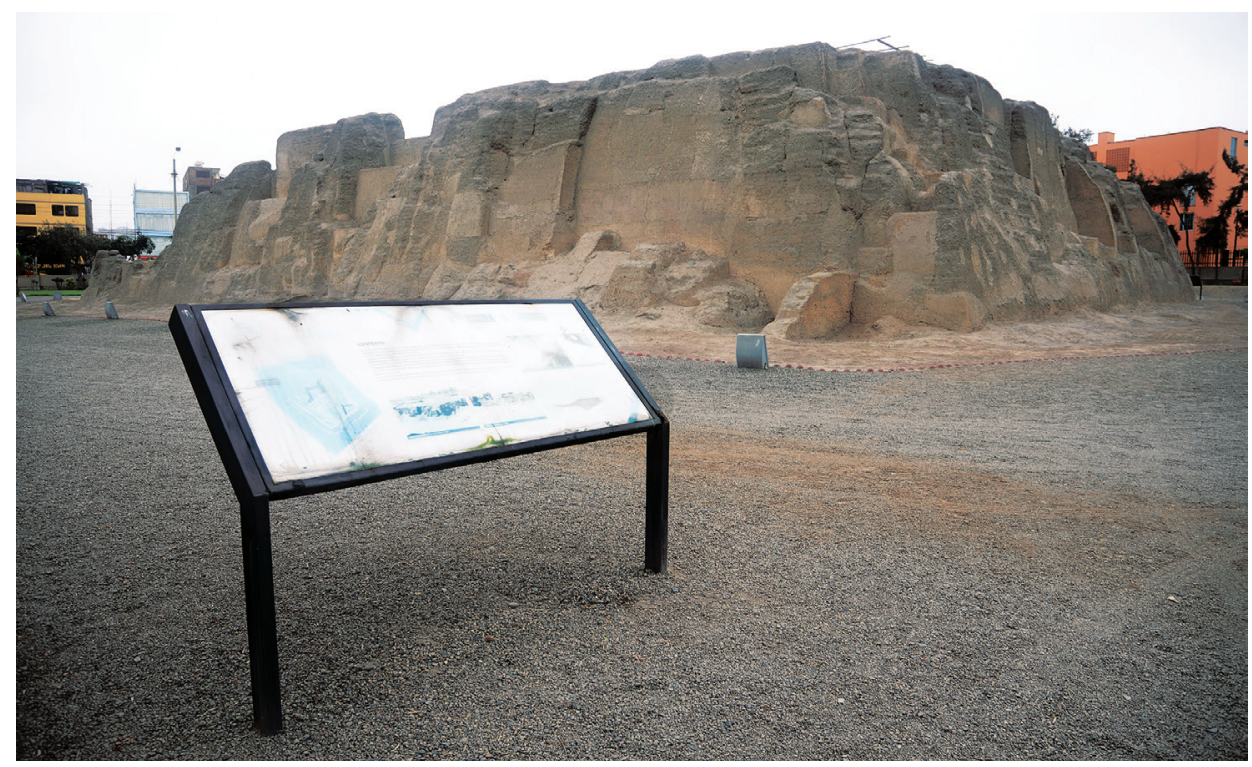

Figura 14. Señalización deteriorada por falta de uso y mantenimiento. Archivo fotográfico personal de W. Silvera, 2017.

Es importante destacar que la puesta en valor de un monumento estrecha la relación de la comunidad con el patrimonio y fortalece la identidad, especialmente en los niños y jóvenes, porque son ellos quienes tendrán la oportunidad de desarrollarse e interactuar en espacios de cultura viva, y aprenderán a respetarlos y protegerlos, como menciona el arqueólogo Carlos Rea en su tesis Puesta en Valor de la Huaca San Borja (2003).

Igual que en el periodo anterior la figura se repite: el arqueólogo que dirige el proyecto, en este caso Carlos Rea, considera que, a falta de apoyo institucional, la labor de un gestor es conseguir los recursos necesarios para realizar los trabajos, los cuales no necesariamente se dan mediante la ejecución de un plan. En este segundo periodo, es más clara la figura de que todo el trabajo realizado estuvo dirigido a que revierta a la sociedad, por lo que se incorporó la participación, aunque sesgada, de los vecinos.

Querol \& Martínez (1996) afirman sobre la gestión del patrimonio lo siguiente: "Partimos del principio de que ninguna actividad arqueológica del tipo que sea puede llevarse a cabo de forma adecuada sin planificación previa -y esa planificación es ya en sí una actividad de gestión-" (p. 208).

Aunque no existen documentos que permitan saber con exactitud cuánto se avanzó respecto de lo planificado, sí se conoce que el trabajo realizado permitió que la huaca pueda ser usada, aunque existan observaciones. Solo se cuenta con el testimonio de Rea, quien manifiesta haber recibido el monumento en condiciones lamentables, y haber realizado una dura tarea de consolidación. Durante esta etapa de intervención, se produjo un acondicionamiento del espacio y se desarrolló una propuesta museográfica; los testimonios y trabajo efectuado así lo demuestran.

\section{Gestión 2011-2016}

En el año 2011, el arqueólogo Carlos Rea fue retirado de sus labores en la Huaca San Borja. Este hecho estuvo relacionado con el desmantelamiento del Museo de la Nación, que en el año 2014 se desactivó totalmente. Se desconocen los motivos de la paralización de los trabajos. 
Entre 1986 y 2010, el Municipio Provincial de Lima no había tenido mayor injerencia con respecto a la preservación del patrimonio arqueológico. En 2011 la gestión de Susana Villarán lanzó un ambicioso programa, Vamos a las Huacas, que se desarrolló entre los años 2012 y 2014. Además, se realizó un convenio de cooperación interinstitucional entre el Ministerio de Cultura y la Municipalidad Metropolitana de Lima, denominado "Plan: Mi Huaca Herencia que Nos Une", celebrado el 24 de julio de 2012, el cual da sustento legal a las nuevas labores de gestión. Con ello, se buscaba proteger, investigar, conservar, poner en valor, difundir y promover el uso social responsable de los monumentos arqueológicos.

Por su parte, el Ministerio de Cultura, a través de su Dirección de Gestión de Monumentos, llevó a cabo el programa La Huaca Nos Cuenta, dirigido a niños de 4 a 9 años con el objetivo de que identifiquen su patrimonio arqueológico a través de actividades lúdicas como las visitas guiadas, la narración de cuentos, los talleres creativos y una actividad final denominada El Abrazo a la Huaca.

El arqueólogo Elvis Mondragón (comunicación personal, 25 de agosto de 2017), de la Dirección de Gestión de Monumentos del Ministerio de Cultura, manifiesta que en el marco de esos programas se realizaron tres cuentacuentos y tres ediciones de La Huaca Nos Cuenta, dirigidos a los colegios de San Borja y San Luis. Además, se desarrollaron actividades culturales como los raymis y un último evento celebrado por el Día Internacional del Yoga, actividades que no cuentan actualmente con registro.

De acuerdo a una información publicada en 2015 en el portal de noticias El Útero, la Huaca San Borja estaba funcionando como estacionamiento. Esta situación habría recibido el rechazo de los arqueólogos del Ministerio de Cultura, pero de acuerdo a la nota periodística, la alta dirección así lo había autorizado.

Respecto de este último periodo no es posible deducir un modelo de gestión desde el Ministerio de Cultura con respecto a la huaca; más bien, resalta un hecho insólito que surgió como iniciativa del Gobierno Municipal Metropolitano, normalmente ajeno a asuntos vinculados al patrimonio arqueológico, que tenía un plan para crear una Unidad de Gestión del Patrimonio Arqueológico de la Municipalidad Metropolitana de Lima, cuya fundamentación se amparaba en la siguiente lógica:

En este contexto la demanda por espacios culturales y la atención de los centros arqueológicos de la ciudad, como una alternativa de aprehensión ciudadana del legado cultural prehispánico de la ciudad han ido incrementándose... Es por ello que la Municipalidad de Lima Metropolitana ha reconocido el potencial y momento expectante por el que pasa el patrimonio arqueológico de la ciudad, y asume cabalmente su liderazgo en este campo. (Municipalidad Metropolitana de Lima, 2013, pp. 2-3)

El plan de acción propuesto busca generar mecanismos que permitan poner la huaca en valor para su uso social, por ejemplo, creando circuitos turísticos y educativos. Para ello es necesario que esa unidad de gestión asuma creativamente los lineamientos generales que orienten su accionar, teniendo como fundamento la investigación, conservación y gestión. Sus objetivos principales son tres:

a. Generar un discurso de valor cohesivo, en el cual el patrimonio arqueológico de la ciudad sea visto como el origen urbano de Lima.

b. Desarrollar una plataforma de comunicación, y difusión masiva e informatizada que permita actualizar de manera permanente la información sobre los sitios arqueológicos de la ciudad, la historia sobre sus investigaciones y las iniciativas ciudadanas (públicas y privadas) a favor de ellos. 
devenir Vol. 6, Nº11, ENERO - JUNIO 2019, PP. 107-128 - ESTUDIOS I ISSN 2312-7562 | E-ISSN 2616-4949

UNIVERSIDAD NACIONAL DE INGENIERÍA, LIMA

doi: https://doi.org/10.21754/devenir.v6i11.636

c. Ejecutar o coadyuvar a la ejecución de proyectos de investigación, conservación y puesta en valor del patrimonio arqueológico de la ciudad. Ello incluye la formalización de circuitos turísticos, construcción, administración y/o apoyo a museos o centros de información, programas educativos, entre otros. (Municipalidad Metropolitana de Lima, 2013, p. 3)

Por primera vez, puede observarse una intención clara de planificar y conducir una política de puesta de uso social de las huacas de Lima en general, bajo la conducción del Municipio Metropolitano, que pusieron las partidas necesarias para desarrollar este plan de gestión.

La Municipalidad de Lima asumió en la práctica el expertise técnico-administrativo del equipo de arqueólogos del Patronato del Parque de las Leyendas (PATPAL), cuya trayectoria resume casi 20 años de labores en el sitio. En otras palabras, se buscó mantener una continuidad y se valoró la experiencia (Tabla 1).

\section{Interpretación de los resultados}

Luego de revisar los documentos, entrevistas y contrastar esa información con el estado actual de la huaca, es posible afirmar que en ninguna de las tres etapas en que se intervino el monumento arqueológico se alcanzaron los objetivos que se señalaron en su momento. En todos los casos, se pretendió ponerla en valor, pero como suele ocurrir en la gestión estatal, cada administración olvidó lo que hizo la anterior y volvió a empezar, como en el mito griego de Sísifo. El último periodo (2011-2016) fue el que más se acercó al objetivo de acondicionar la huaca para el uso social.

No se encontraron documentos de ninguna de las etapas de gestión donde se estipularan avances o metas; tampoco hay instrumentos de medición, situación que dificulta la evaluación de la labor en cada periodo de intervención. Es necesario señalar que sobre este punto ni la academia ni los órganos del gobierno se pronunciaron (durante el periodo de intervención ni después).

La participación de entidades públicas y privadas (gobiernos locales, gobierno central e instituciones académicas) se desarrolló sin inconvenientes. Es posible resaltar la suma de esfuerzos, la convocatoria y la voluntad de participar. Los procesos de intervención en la huaca pudieron convocar a actores de diversas disciplinas, con diferentes intereses y obligaciones. La tarea de poner en uso social a las huacas de Lima requerirá el concurso de todos.

Los gestores encargados de la huaca, en cada periodo, asumieron el reto como un tema personal. Todas las acciones realizadas fueron gracias a la habilidad y a la red de contactos de cada uno de ellos. Si bien esto demuestra su compromiso con el trabajo asignado, estas tareas deberían estar acompañadas y respaldadas por una gestión institucional. Los marcos legales que se firmaron no fueron suficientes para garantizar la puesta en valor de la Huaca San Borja. Ni la crisis económica más severa del siglo XX (periodo 1985-1990) pudo detener la intervención en la huaca, pero la falta de institucionalidad y sucesos como el cierre del Museo de la Nación retrasaron las obras (Tabla 2).

\section{Conclusiones}

Tras analizar los distintos procesos de gestión implementados en la Huaca San Borja, es posible afirmar que, a pesar de su ubicación estratégica, próxima al nodo metropolitano llamado Centro Cultural de la Nación, conformado por la Biblioteca Nacional del Perú, el Gran Teatro Nacional, el Ministerio de Cultura, el Centro de Convenciones de Lima y el Ministerio de Educación, además de corredores viales como la Estación La Cultura de la Línea 1 del Metro de Lima, y las avenidas Javier Prado y Canadá, no se ha logrado poner a la denominada huaca en uso social. 
Penumbra sobre la zona cultural de Lima. Análisis de los procesos de gestión de la Huaca San Borja (Lima-Perú) entre los años $1986-2016$ Peruska Chambi Echegaray, luis Donayre Chiu, Rosario García Quispe, Aldo lértora Carrera y Walter Silvera Prado

doi: https://doi.org/10.21754/devenir.v6i11.636

Tabla 1. Análisis cronológico de los componentes gestionarios de la Huaca San Borja sobre la base de la información detallada en cada proceso de gestión, considerando Actores, Marco legal y Administración de la huaca

\begin{tabular}{|c|c|c|c|}
\hline Periodos de gestión & $1986-2000$ & $2000-2011$ & $2011-2016$ \\
\hline \multirow{7}{*}{ Actores } & - Municipalidad de San Borja & $\begin{array}{l}\text { - Dirección de Investigación, Museo } \\
\text { de la Nación }\end{array}$ & - Municipalidad de Lima \\
\hline & - Arqueólogo Alberto Bueno & - Arqueólogo Carlos Rea & \multirow[t]{6}{*}{ - Ministerio de Cultura } \\
\hline & - Instituto Nacional de Cultura INC & $\begin{array}{l}\text { - Facultad de Ingeniería Civil, Universi- } \\
\text { dad Nacional de Ingeniería }\end{array}$ & \\
\hline & - Universidad de Lima & - Universidad Federico Villarreal & \\
\hline & - Universidad San Marcos & $\begin{array}{l}\text { - Taller Interdisciplinario de Ciencias } \\
\text { Sociales de la Universidad San Marcos }\end{array}$ & \\
\hline & & - Municipalidad de San Borja & \\
\hline & & - Plan Copesco & \\
\hline Marco legal & $\begin{array}{l}\text { Convenio de Cooperación Cultural } \\
\text { firmado entre la Municipalidad de } \\
\text { San Borja y la Universidad de Lima } \\
\text { en } 1987 .\end{array}$ & $\begin{array}{l}\text { No se realizaron convenios de } \\
\text { cooperación con ninguna institución } \\
\text { pública ni privada. }\end{array}$ & $\begin{array}{l}\text { Convenio de Cooperación } \\
\text { Interinstitucional entre el Ministerio } \\
\text { de Cultura y la Municipalidad Metro- } \\
\text { politana de Lima denominado "Plan: } \\
\text { Mi Huaca Herencia que nos une", } \\
\text { celebrado el } 24 \text { de julio del } 2012 \text {. }\end{array}$ \\
\hline Administración & $\begin{array}{l}\text { - La administración recayó en el } \\
\text { Arqueólogo Alberto Bueno, Direc- } \\
\text { tor Técnico del proyecto. } \\
\text { - La Universidad de Lima se encar- } \\
\text { gada de los gastos del personal. }\end{array}$ & $\begin{array}{l}\text { El Arqueólogo Carlos Rea interviene la } \\
\text { huaca bajo el encargo de la Dirección } \\
\text { de Investigaciones del Museo de la } \\
\text { Nación con el "Proyecto Institucional } \\
\text { de Investigación Arqueológica y Pues- } \\
\text { ta en Valor Huaca San Borja”. }\end{array}$ & $\begin{array}{l}\text { Ministerio de Cultura a través de la } \\
\text { Dirección de Gestión de Monumen- } \\
\text { tos. }\end{array}$ \\
\hline
\end{tabular}

Elaboración propia, 2018.

Tabla 2. Características de los diferentes procesos de gestión sobre la base de la información obtenida en entrevistas y documentos

$$
1986-2000
$$

$2000-2011$

$2011-2016$

Objetivo: Puesta en valor para crear un Centro Cultural.

No hubo etapas medibles.

Intervención de entidades públicas y privadas.

No se llegó a la meta.

Este proceso terminó cuando concluyó el convenio.

Gestión como mérito del interventor.
Objetivo: Investigación y Puesta en valor.

No hubo etapas medibles.

Intervención de entidades públicas y participación vecinal.

No se llegó a la meta.

Este proceso terminó cuando se cerró el Museo de la Nación.

Gestión como mérito del interventor.
Objetivo: Puesta en valor para el uso social.

No hubo etapas medibles.

Intervención de entidades públicas y la participación por primera vez de la Municipalidad de Lima.

Se encuentra en uso, pero no en su totalidad.

El proceso está inconcluso. Hasta la fecha no se terminan las obras.

Administrado por el Ministerio de Cultura. 
devenir Vol. 6, Nº11, ENERO - JUNIO 2019, PP. 107-128 - ESTUDIOS I ISSN 2312-7562 | E-ISSN 2616-4949

UNIVERSIDAD NACIONAL DE INGENIERÍA, LIMA

doi: https://doi.org/10.21754/devenir.v6i11.636

La Municipalidad de San Borja ni el Ministerio de Cultura han podido integrarla en un circuito cultural, por lo que actualmente permanece aislada, a pesar de los avances respecto de la puesta en valor, como la instalación del centro de interpretación, iluminación y señalización. Además, los programas para escolares promovidos por la Municipalidad de Lima en la huaca no tomaron en cuenta a los niños de la zona, con lo que se perdió la oportunidad de convertirlos en aliados en la defensa del monumento.

Si la gestión es, en cierta medida,

El manejo de algo que se administra para que genere los mejores resultados posibles. En el ámbito del patrimonio cultural, esta gestión deberá administrar más allá de la superación del deterioro y/o anulación, repotenciando procesos de rehabilitación, reconocimiento y disfrute por y para todos, convirtiéndose en un verdadero elemento de desarrollo. (Hayakawa, 2016, p. 37)

Así, puede sostenerse que la gestión de la Huaca San Borja solo cumplió su trabajo de manera sesgada. Se intervino la huaca para investigarla, se consolidó, se acondicionó y parcialmente se puso en valor, pero a pesar de ello su destino final, en 2015, fue servir de cochera de funcionarios de la alta dirección del Ministerio de Cultura.

Estos procesos de gestión inconclusos se relacionan con la falta de institucionalidad de la que adolece el Estado. No se ha identificado continuidad entre las tres etapas en la que se intervino la huaca. Entre 1986 y 2016 aparecieron y desaparecieron instituciones que afectaron su puesta en valor. El Estado peruano tiene falencias en cuanto a la elaboración de protocolos o planes de gestión del patrimonio monumental, que funjan de guía o norte para orientar el trabajo. Por tanto, evaluar los avances, intenciones o resultados es una tarea difícil.

La responsabilidad no es de los gestores, quienes en la intervención vieron un camino para rescatar a la huaca del abandono y de su posible desaparición; la responsabilidad es de los gobiernos y del Estado, para quienes no resulta fundamental tener un plan nacional de gestión del patrimonio monumental.

La huaca tiene un gran poder de convocatoria, suscita interés como materia de estudio y supone una oportunidad para el encuentro académico de diversas disciplinas. Es importante destacar que, durante los procesos de intervención, participaron muchos estudiantes universitarios, cuyos conocimientos y experiencia fueron valiosos para los avances en la puesta en valor.

El manejo político también ha jugado un papel fundamental en torno a la suerte de la huaca: el abanico de opiniones e intervenciones es muy amplio. Desde 1987 todas las autoridades locales se han hecho fotos en el lugar, pero no se ha percibido un real compromiso con este patrimonio. Probablemente sea en las épocas de elecciones cuando más se piense en la huaca, pero no por el monumento en sí mismo, sino por los vecinos votantes. Existe casi una nula visión sobre el potencial del lugar. En el plano nacional, casi no existen políticos o partidos interesados en el patrimonio cultural o la cultura en general; todo su quehacer se reduce a índices de rentabilidad. Por ello, el Plan de Gestión de Patrimonio Arqueológico para la Ciudad de Lima para el periodo 2012-2014 es toda una rareza en el mar de la indiferencia en que se mueve la política peruana.

\section{Referencias}

Azkarate, A., Ruiz de Ael, M., \& Santana, A. (2003). El Patrimonio Arquitectónico [Ponencia presentada al Plan Vasco de Cultura]. Vitoria-Gasteiz: Servicio Central de Publicaciones del Gobierno Vasco.

Ballart, J., \& Tresserras, J. (2001). Gestión del Patrimonio Cultural (1 ed.). Barcelona, España: Ariel, pp 238. 
Penumbra sobre la zona cultural de Lima. Análisis de los procesos de gestión de la Huaca San Borja (Lima-Perú) entre los años $1986-2016$ Peruska Chambi Echegaray, luis Donayre Chiu, Rosario García Quispe, Aldo lértora Carrera y Walter Silvera Prado

doi: https://doi.org/10.21754/devenir.v6i11.636

Bonavia, D., Matos R. \& Caycho F. (1962-63). Informe sobre los monumentos arqueológicos de Lima. Junta Deliberante Metropolitana de Monumentos Históricos, Artísticos y Lugares Arqueológicos de Lima. Lima. Número 2.

Bueno Mendoza, A. (2016). Excavaciones y estudios etnohistóricos del Monumento Arqueológico San Borja Norte, Valle de Lima. Arqueología y Sociedad, Número 31, 423-464.

Consejo Internacional de Monumentos y Sitios. (1990). Carta Internacional para la Gestión del Patrimonio Arqueológico. Recuperado de https://www.icomos.org/images/DOCUMENTS/ Charters/arch_sp.pdf

Cornejo, C. (2013). La arquitectura precerámica monumental en la costa central: la tradición EI Paraíso. Investigaciones Sociales, 17(30), 125-129.

Espinoza, V. (2014). La etnia Ishma (Ychsma, Ichma, Ichmay). Investigaciones Sociales, 13(32), $117-159$

Florescano, E. (1993). El Patrimonio Cultural de México (1 ed.). México: Fondo de Cultura Económica, pp. 424.

Hayakawa, J. (2016). Gestionando el Patrimonio Edificado de Lima. Apuntes para la construcción de un marco teórico. Turismo y Patrimonio - Universidad de San Martín de Porres, (10), 29-39.

Hidalgo, L. (2011, 24 de enero). Este año pondrán en valor 10 huacas en Lima para impulsar turismo. Gestión. Recuperado el 16 de abril de 2019, de https://plancopesconacional.gob.pe/ archivos/Noticia_00_2011_Articulo_Gestion.pdf

Huaca. (s.f.). En Diccionario de la lengua española. Recuperado el 8 de Diciembre de 2018, de http://dle.rae.es/?id=JbFx8qE

Instituto de Investigación, Universidad de San Martín de Porres. (1993). Patrimonio Turístico del Distrito de San Borja. Lima, Perú: Autor.

Instituto Nacional de Cultura - Municipalidad de Lima Metropolitana. (1985). Inventario de Monumentos Arqueológicos del Perú. Lima, pp. 105.

Instituto Nacional de Estadística e Informática. (2018, 21 de setiembre). Lima alberga 9 millones 320 mil habitantes al 2018. Recuperado de https://www.inei.gob.pe/prensa/noticias/ lima-alberga-9-millones-320-mil-habitantes-al-2018-10521/

Laurie, A. (2015, 10 de noviembre). Patrimonio y sector privado. El Comercio. Recuperado el 5 de julio de 2017, de https://elcomercio.pe/lima/patrimonio-sector-privado-angus-laurie-240784

Lértora, A. \& Martínez, M. (1996). Restauración de la Iglesia y Casa Hacienda de San Juan Grande de Surco. Arkinka, 1(3), 70-84.

Llanos, L. (2018, 7 de noviembre). Un Patrimonio Histórico estaba funcionando como estacionamiento (y el Ministerio de Cultura lo autorizó). Recuperado de (http://utero.pe/2015/10/01/ un-patrimonio-historico-estaba-funcionando-como-estacionamiento-y-el-ministerio-de-cultura-lo-autorizo/

Macera, P. (2007). La vocación por la Historia y otros temas. Tiempos, (2), 77-100. Recuperado el 22 de junio de 2017 de https://issuu.com/rchuhue/docs/macera

Municipalidad de San Borja. (2018, 1 de octubre). Portal Institucional Municipalidad de San Borja. Unidad de Educación, Cultura y Turismo. Recuperado de http://www.munisanborja.gob.pe/ cultura/turismo/resena-del-distrito.html

Municipalidad Metropolitana de Lima. (2012). ¿Cuántas Huacas? Recuperado el 13 de agosto de 2017 de http://www.munlima.gob.pe/lima-milenaria/cuantas-huacas

Municipalidad Metropolitana de Lima. (2013a). Resumen de Gestión del Patrimonio Arqueológico de Lima. Recuperado el 8 de diciembre de 2018 de http://docplayer.es/29815797-Gerencia-de-cultura-resumen-del.html

Municipalidad Metropolitana de Lima. (2013b). Taller de Arte y Arqueología en la Huaca San Borja. Recuperado el 12 de Noviembre de 2018, de https://motivosdesobra.files.wordpress. com/2014/11/guia_para_docentes_huaca_san_borja.pdf 
devenir Vol. 6, №11, ENERO - JUNIO 2019, PP. 107-128 - EstudIOS I ISSN 2312-7562 | E-ISSN 2616-4949

UNIVERSIDAD NACIONAL DE INGENIERÍA, LIMA

doi: https://doi.org/10.21754/devenir.v6i11.636

Pérez-Juez, A. (2006). Gestión del patrimonio arqueológico: El yacimiento como recurso turístico. Barcelona, España: Ariel.

Querol, Á., \& Martínez, B. (1996). Las actividades arqueológicas de gestión: Planificación, difusión y control. En La gestión del patrimonio arqueológico en España. Madrid, España: Alianza Editorial, pp. 205-226.

Ravines, R. (Octubre de 1975). Garagay. Un viejo templo en los andes. Revista del Instituto Nacional de Cultura(10), pp. 17.

Rea, C. (2003). Puesta en valor de la Huaca San Borja. Lima, Perú: Universidad San Martín de Porres.

Rea, C. (2007, junio - julio). Complejo Arqueológico Huaca San Borja. Ejemplo de recuperación. Gaceta Cultural - Instituto Nacional de Cultura, Número 28, p. 21.

Vegas de Cáceres, I. (1996). Economía rural y estructura social en las haciendas de Lima durante el siglo XVIII. Lima, Perú: Fondo Editorial Pontificia Universidad Católica del Perú. 